\title{
Unspoken SPS-Plus and SPS-Minus Aspirations: Biotechnologies in EU and US Trade Agreements
}

\author{
Filippo FONTANELLI* $*$
}

In the World Trade Organization (WTO), the US approach to science-based risks and trade restrictions prevailed over that of the European Union (EU). The EU, dissatisfied with the margin of action available when "relevant scientific evidence is insufficient", largely kept intact its internal practice on marketing and importing genetically modified (GM) crops and GM-containing products. The goal of this article is to ascertain whether these regulatory preferences of the US and the EU translate into their post-Biotech external trade efforts. US and EU preferential trade agreements are scanned for rules on trade in biotechnology goods or the use of precautionary elements in regulation. It transpires that neither bloc systematically tries (or manages) to bend trade agreements to accommodate its defensive or offensive trade interests in this field. Among the possible reasons for this apparent inertia are the US confidence in the WTO baseline and the EU preference for a "don't ask, don't tell" approach to its trade-restrictive policy in this area.

\section{INTRODUCTION}

In 2009, the European Union (EU) banned all imports of flax (linseed) from Canada for four months, after some genetically modified (GM) flax was detected in one shipment from Canada. The ban remained in force until a stewardship testing protocol was put in place to ensure compliance with EU rules. The ban and protocol cost money and jobs to the Canadian flax-production industry and the EU flax-importation and processing industries. ${ }^{1}$ In 2019 , Canada asked the EU to "adopt a pragmatic approach to LLP [unintentionally low level presence of GM crops] to avoid unnecessary disruptions to trade". ${ }^{2}$

The LLP controversy spans a decade of EU-Canada trade relations and serves as a textbook example of a regulatory barrier to trade. Yet scholars of the law of the World Trade Organization (WTO) might have missed it, despite their passion for

\footnotetext{
School of Law, University of Edinburgh, UK and LUISS, Rome, Italy; email: filippo.fontanelli@ed.ac.uk.

1 CD Ryan and SJ Smyth, "Economic implications of low-level presence in a zero-tolerance European import market: the case of Canadian triffid flax" (2012) 15(1) AgBioForum 21; A Arcuri, "Is CETA keeping up with the promise? Interpreting certain provisions relating to Biotechnology" (2017) 41 Questions of International Law, Zoom-Out 39.

2 CETA, Dialogue on Biotech Market Access Issues, 11th meeting, 4 March 2019.
} re-use, distribution, and reproduction in any medium, provided the original work is properly cited. 
trade incidents. In fact, WTO law on trade in GM products has not evolved much since the Biotech reports of $2006 .^{3}$ Whither has international trade law gone? ${ }^{4}$

This article does not rehash the Biotech dispute, its precursor story ${ }^{5}$ and its outcome. The EU's compliance is not its focus either. ${ }^{6}$ Instead, I use Biotech as a cut-off point to assess how international trade law has evolved since, alongside the EU and US efforts to build their preferential trade networks. This enquiry builds on a factual baseline: the EU lost on the multilateral WTO stage, but it has not been keen to abandon its policy on GM products; the US won. Both actors could turn to bilateral or plurilateral instruments outside the WTO (including free trade agreements, or FTAs); the EU to limit the damage of its defeat, and the US to expand the effects of its victory. ${ }^{7}$

The WTO has no specific document or rule about trade in GM products. When WTO members adopt rules that restrict or ban their marketability on grounds of public health, the 1995 Agreement on the Application of Sanitary and Phytosanitary measures (SPS Agreement) remains the applicable instrument. ${ }^{8}$ Under the SPS Agreement, policies and approaches whose sole rationale is precaution (or "public anxiety") are not warranted. The goal of this article is to investigate whether the EU and the US have engaged in a standard-setting race outside the WTO, ${ }^{10}$ each pursuing its own SPSplus or SPS-minus objectives. ${ }^{11}$ Popular opinion describes the world dividing into Team EU and Team US:

the epic battle about the "precautionary principle" has ... split the world into Genetically Modified Organisms (GMO)-free and GMO-using world regions, and an EU-USA compromise is not in sight, not now and not in TTIP. ${ }^{12}$

\footnotetext{
3 Panel Reports, European Communities - Measures Affecting the Approval and Marketing of Biotech Products, (Biotech), WT/DS291/R, WT/DS292/R, WT/DS293/R, adopted September 2006.

4 Arguably, the latter segments of the Hormones dispute can shed some light on issues relevant to GM trade, such as the features of risk assessment; see Appellate Body Reports, Canada/United States - Continued Suspension of Obligations in the EC - Hormones Dispute, WT/DS320/AB/R, WT/DS321/AB/R, adopted 14 November 2008, para 534.

5 Y Tiberghien, "Competitive governance and the quest for legitimacy in the EU: the battle over the regulation of GMOs since the mid-1990s" (2009) 31(2) European Integration 389.

6 MJ Punt and J Wesseler, "Legal but costly: an analysis of the EU GM regulation in the light of the WTO trade dispute between the EU and the USA" (2016) 39(1) The World Economy 158-69.

7 For a recent study of defensive and offensive strategies in FTAs, see C Brandi, J Schwab, A Berger and J-F Morin, "Do environmental provisions in trade agreements make exports from developing countries greener?" (2020) 129 World Development 866.

8 On the SPS Agreement and the permissibility of precautionary measures, see L Gruszczynski, Regulating Health and Environmental Risks under WTO Law: A Critical Analysis of the SPS Agreement (Oxford, Oxford University Press 2010) pp 157-217; J Scott, The WTO Agreement on Sanitary and Phytosanitary Measures: A Commentary (Oxford, Oxford University Press 2009) pp 109-26; PC Mavroidis, The Regulation of International Trade, Volume 2. The WTO Agreements on Trade in Goods (Cambridge, MA, MIT Press 2016) pp 483-88.

9 ibid, 487.

10 C-F Lin, "Bilateral treaty network: a 'global' solution to the global food safety problem?" (2012) 29 Wisconsin International Law Journal 694; O Osiemo, "Saving Africa: the GMO cold war and the battle for Africa" (2018) 52(1) Journal of World Trade 143

11 M Wagner, "The future of sanitary and phytosanitary governance: SPS-plus or SPS-minus" (2017) 51(3) Journal of World Trade 445.

12 A Melchior, Free Trade Agreements and Globalisation (London, Palgrave Macmillan 2018) p 84.
} 
Assuming this picture is accurate, are the two leaders trying to recruit members for their teams? The working hypotheses are as follows: the EU, in its post-Biotech FTAs, must have tried to cope with the fallout. ${ }^{13}$ The EU does not export any GM crops or plants, and the very limited local production goes into animal feed and biofuels. To make sense for the EU, new trade agreements must safeguard a defensive interest: the EU would not rationally self-inflict the blow of freer trade in these products. Conversely, the US must have tried to consolidate the ratio of the Biotech report in its external economic action to support its exporting goals.

This article sets out these working hypotheses and tests their accuracy against the record of the US and EU in drafting FTAs. Section II outlines the EU's regulatory reaction to Biotech to explain its reluctance to open up to GM foodstuffs. Section III clarifies the extent to which FTAs and other international trade law instruments can effectively develop, or detract from, the rules of the SPS Agreement. Section IV surveys post-Biotech agreements of the EU and the US to glean their respective approaches. In Section V, I contrast the FTAs that the EU and the US have concluded with the same third countries: Canada, Japan and South Korea. A note of caution is sounded with respect to trade with African countries.

The conclusions will articulate the findings: the US is slowly but inevitably prevailing in setting trade standards for trade in biotechnologies globally, as far as health-related regulations are concerned. ${ }^{14}$ The EU must negotiate with external constraints - in particular its WTO obligations - and its safest course of "defensive" action is often to leave the matter outside FTAs altogether. The US carefully monitors new technologies and solicits consensus on their efficiency and marketability, trying to defuse the risk that precautionary temptations take over novel matters. Ultimately, neither party appears to use FTAs aggressively to advance their biotechnology agenda: a low-intensity approach appears to serve them well enough.

\section{EU'S POST-BIOTECH MEASURES}

The story of the Biotech dispute before the WTO and its systemic relevance are well known. Argentina, Canada and the US prevailed over the EU. This simple story begets simplification: under WTO law, science-based approaches to risk management are permitted; however, restrictive measures addressing unproven risks are not, even if they reflect local social preferences. This is a reductionist characterisation of the transatlantic divide on risk management, ${ }^{15}$ but it might be good enough for the purpose of this study. In the EU, risk management is based on science, in principle. However, when "scientific evaluation does not allow the risk to be determined with

\footnotetext{
13 D Blümer et al, "Environmental provisions in trade agreements: defending regulatory space or pursuing offensive interests?" (2020) 29(5) Environmental Politics 866, 872, referring specifically to environmental disputes: "When one of these ... disputes arises over an environmental regulation, it is not uncommon that the responding countries will introduce a new defensive provision in their subsequent [preferential trade agreements] and that third countries will pay attention and follow suit to avoid being targeted as well".

14 Conversely, precaution in environmental regulations is still widely upheld as an operating principle, but it rarely matters for the lawfulness of trade measures and, therefore, has no real trade teeth.

15 M Herdegen, The International Law of Biotechnology (Cheltenham, Edward Elgar 2018).
} 
sufficient certainty", it is possible to base protective measures on "preliminary objective scientific evaluation". ${ }^{16}$ At stake here are the different approaches of the EU and US at the margins; that is, where their views differ the most, such as in the management of the adventitious or low-level presence of GM organisms (GMOs), a scenario intimated above.

Ultimately, the Biotech story had a clear outcome. The EU lost, and it was ordered to bring its restrictions against GM crops and foodstuff into compliance with WTO law. There has not been further litigation before the WTO on the matter. Yet the EU's opening to GMO products since has been reluctant at best.

After the Biotech report, the EU established a system of authorisation for cultivating or importing GM foodstuffs and GM-containing products. ${ }^{17}$ The EU lifted the de facto blanket ban found unlawful by the WTO, but the complexity of the supervening authorisation process, comprising a myriad of steps and institutions, is daunting. ${ }^{18}$ Even when the European Commission authorises cultivation, Member States can opt out, invoking grounds other than health and environmental protection ${ }^{19}$; most Member States have used this option. ${ }^{20}$ Whether this regime deliberately stifles or frustrates applications is beyond the point. The fact, evidently, is that access of GMOs to the EU markets is possible in theory but practically arduous. The EU regulations minimise the effects of Biotech, making the penetration of GM seeds and foodstuffs very sparse.

Moreover, the EU has adopted a low- or no-tolerance approach to the adventitious or low-level presence of GMOs in imported feed and food. This approach hampers the trade of GMO-free foodstuffs coming from countries in which GM crops are lawful and, therefore, accidental cross-contamination can happen. Finally, the EU Court of Justice has found that "organisms obtained by mutagenesis" qualify as GMOs and therefore must enter the labyrinthine approval system just described. ${ }^{21}$

\footnotetext{
16 Communication from the Commission on the precautionary principle (COM(2000) 1 final (2 February 2000); J Tosun, "How the EU handles uncertain risks: understanding the role of the precautionary principle" (2013) 20(10) Journal of European Public Policy 1517-28; R Lofstedt, "The precautionary principle in the EU: why a formal review is long overdue" (2014) 16(3) Risk Management 137-63. For comparative views of the various national approaches and regulations, see D Hamburger, "Comparative analysis: the regulation of plants derived from genome editing in Argentina, Australia, Canada, the European Union, Japan and the United States", in H-G Dederer and D Hamburger (eds), Regulation of Genome Editing in Plant Biotechnology: A Comparative Analysis of Regulatory Frameworks of Selected Countries and the EU (Berlin, Springer 2019) p 313; J Zander, The Application of the Precautionary Principle in Practice: Comparative Dimensions (Cambridge, Cambridge University Press 2010).

17 Punt and Wesseler, supra, note 6, $164 \mathrm{ff}$; Arcuri, supra, note 1, 39.

18 M Weimer and G Pisani, "The EU adventures of 'Herculex': report on the EU authorization of the genetically modified maize 1507" (2014) 5 European Journal of Risk Regulation 208, 208-12; S Poli "The reform of the EU legislation on GMOs: a journey to an unknown destination?” (2015) 6 European Journal of Risk Regulation 559.

19 Directive 2001/18/EC, amended in 2015, see Art 26b, establishing the grounds for safeguards, including environmental policy, town and country planning, land use and socioeconomic impacts.

20 See US Statement at the WTO DSB Meeting in Geneva, 18 December 2019, mentioning "at least seventeen EU member states" seeking to block cultivation of MON-810 maize. See also US Foreign Agricultural Service, Agricultural Biotechnology Annual Report - European Union (31 December 2020) at <apps.fas.usda.gov>, 10, reporting that "Nineteen MS have 'opted out' of GE crops cultivation since 2015". On the aborted plan to also permit Member States to ban marketability (not just cultivation), see B Salas Ferer, "The European Commission's GMO opt-out for Member States: a WTO perspective" (2016) 7(1) European Journal of Risk Regulation 187.

21 C-528/16, Confédération paysanne and Others v Premier ministre and Ministre de l'agriculture, de l'agroalimentaire et de la forêt, judgment of 25 July 2018, ECLI:EU:C:2018:583. The US immediately raised a trade concern under the SPS, see STC no. $452<$ http://spsims.wto.org/en/SpecificTradeConcerns/View/452>. See $\mathrm{K}$ Purnhagen and J Wesseler, "EU regulation of new plant breeding technologies and their possible economic implications for the EU and beyond" (2020) Applied Economic Perspectives and Policy 1-17.
} 
This regime disperses the elements of any potential WTO illegality across several actors and processes. The approval process and the opt-out decisions might be, on occasion, arbitrary or might drag on, causing undue delays and regulatory barriers obstructing GM foodstuffs lawfully marketed outside the EU, ${ }^{22}$ like the moratorium that triggered the Biotech dispute.

Alongside its convoluted regulations on GM crops and GM-containing products, the EU is actively embracing the strategy of promoting organic agriculture. This strategy can affect the competitive relationship between organic and GM substitutable products, with predictable trade-restrictive effects. ${ }^{23}$ The Commission, with its customarily anodyne and feel-good language, acknowledged as much, and alluded to the EU mission to prevent the level playing field dilemma; that is, the possibility that free trade might reward foreign low-standard products, making virtuous markets vulnerable to their competitive advantage:

The EU is the biggest importer and exporter of agri-food products ... in the world. The production of commodities can have negative environmental and social impacts in the countries where they are produced. Therefore, efforts to tighten sustainability requirements in the EU food system should be accompanied by policies that help raise standards globally, in order to avoid the externalisation and export of unsustainable practices. $^{24}$

However, the point here is not to assess the EU's compliance with the Biotech panel's reports. ${ }^{25}$ The US raises concerns about it at every possible occasion, ${ }^{26}$ but has so far decided not to revamp litigation. The EU has reached a settlement with Argentina and Canada and, therefore, has closed the conflict with them. ${ }^{27}$ Rather, the purpose of this section is to give a glimpse of the EU's continuing practice of restricting the importation and/or use of GM products, honouring a local mainstream socio-political preference. If the EU had just made peace with the notion of opening its market to GMOs, its law-making in FTAs would be uninteresting.

Instead, the EU policies are so entrenched that the EU is ready to go to any length to defend them. See how the EU pleads non-discrimination as an excuse, pretending to ignore that the SPS, unlike the General Agreement on Tariffs and Trade (GATT),

22 For reference, see Panel report, paras 8.13-8.16 and paras 18.17-18.20.

23 In particular, see the recent action plan EU Commission, Farm to Fork Strategy - For a Fair, Healthy and Environmentally-Friendly Food System (2020) 6, at <https://ec.europa.eu/food/sites/food/files/safety/docs/f2f action-plan_2020_strategy-info_en.pdf $>$. On the prospective effects of this strategy on trade in GM products, and how favouring organic food inevitably crowds out GM-substitutable products, see the (fairly partisan) study of KP Purnhagen et al, "Europe's Farm to Fork Strategy and its commitment to biotechnology and organic farming: conflicting or complementary goals?" (2021) 26(6) Trends in Plant Science 600-06.

24 Farm to Fork Strategy, supra, note 23, 6.

25 On this, see Poli, supra, note 18 and Salas Ferer, supra, note 20.

26 WTO, Minutes of Dispute Settlement Body (DSB) meeting of 28 February and 5 March 2020, WT/DSB/M/441, paras 1.13-1.14. The same face-off appears in many previous DSB meetings and all subsequent ones. See Minutes of meeting of 28 September, 26 October and 18 December 2020.

27 WTO, European Communities - Measures Affecting the Approval and Marketing of Biotech Products - Mutually Agreed Solution between Canada and the European Communities (15 July 2009) WT/DS292/40, G/L/628/Add.1; between Argentina and the European Communities (19 March 2010) WT/DS293/41, G/L/629/Add.1. 
also requires regulatory rationality. Answering the recurring complaints about its continued restrictions on GM crops, the EU invariably states:

[t]he European Union had different regulatory approaches to non-GMOs and GMOs but, in all cases, such regulations did not discriminate between imported and domestic like products. ${ }^{28}$

This kind of argument shows that the EU might be deliberately opting for an efficient breach: it values the social benefit of non-compliance more than the legal risks that it carries.

In the following sections, I check whether the EU has tried to protect this strong but legally objectionable internal preference in its post-Biotech FTAs and whether the US, instead, has tried to cement its victory in its own. Given the immobility of WTO lawmaking, countries seeking to consolidate or expand their global regulatory goals (whether defensive or offensive) must pursue their agendas otherwise. For traderelated issues, FTAs are a suitable option.

\section{WHAT CAN BE ACHIEVED WITH PREFERENTIAL ARRANGEMENTS?}

It is necessary at the outset to understand that latitude the US and EU enjoy, under the shadow of WTO law, in their law-making through FTAs. Remember that, as per our working hypothesis, the EU and US are each rationally attracted to a different set of SPS-plus/minus rules (ie provisions on sanitary matters that add to the SPS Agreement or soften its binding edge). ${ }^{29}$ Parallels with the pursuit of the Agreement on Trade-Related Aspects of Intellectual Property Rights (TRIPS)-plus obligations in FTAs are helpful only in part. ${ }^{30}$

\section{FTAs are for liberalisation}

To a basic extent, FTAs can derogate from WTO law, and in particular from its principle of Most-Favoured Nation (MFN) that otherwise proscribes preferential trade between WTO members. WTO law itself, subject to certain conditions, authorises this derogation. ${ }^{31}$ FTAs, however, cannot derogate from all norms of WTO law. FTAs typically deepen trade integration between the participating members by lowering tariffs and regulatory barriers. After all, this is why FTAs are permissible to begin with: if they genuinely cover virtually all trade between two markets, they presumably create trade (rather than merely divert it from third countries). FTAs lower internal trade barriers that remain applicable to goods from non-FTA markets: discrimination in this scenario begets trade, and might just be the first step towards indiscriminate openness. Sometimes, the effects of infra-FTA liberalisation spill over

28 WTO, Minutes of DSB meeting, supra, note 26, para 1.14 .

29 Wagner, supra, note $11,461$.

30 J-F Morin and J Surbeck, "Mapping the new frontier of international IP law: introducing a TRIPS-plus dataset" (2020) 19 World Trade Review 109.

31 Art XXIV GATT. 
onto third countries too. If a WTO member removes a regulatory barrier under an FTA, such as an unnecessary technical or sanitary regulation, the new rules would likely benefit imports from outside the FTA too. TRIPS-plus obligations in FTAs are a good example of the spill-over effect: all copyright holders benefit from an extension of the period of exclusivity beyond the TRIPS baseline, irrespective of their nationality.

Conversely, FTAs typically do not raise internal trade barriers inapplicable to goods from third WTO members. Take precautionary sanitary measures - any such measure, if illegal under WTO law, cannot be justified through an FTA. Even if the FTA parties agreed that such a barrier is acceptable between them, their agreement could not have effects on other countries. ${ }^{32}$ Ultimately, FTAs can contain defensive clauses, which at most reflect the parties' common understanding that certain measures (eg a restriction on the marketing of GMO-containing foodstuffs) are not actionable trade restrictions. WTO members outside the FTA could legitimately challenge the trade hindrance that results from the restrictive measures.

\section{What are SPS-plus obligations?}

As explained, EU FTAs cannot avoid the EU's SPS obligations vis-à-vis WTO membership. At most, they can hint at some reciprocal willingness to tolerate domestic regulatory barriers lacking a solid scientific basis, pursuant to a shared social preference. In its FTAs, instead, the US can insert SPS-plus provisions aimed at affecting its partners' conduct. For instance, FTAs can contain specific commitments to liberalise trade in biotechnologies or scrutinise stringent LLP standards. Rationally, it must be expected that the EU went for "defensive measures" (to protect its rules from complaints), while the US went for "offensive ones" (to instigate change in other countries). ${ }^{33}$

Moreover, if we accept that the SPS Agreement is a non-derogable baseline, it is worth thinking about the content of SPS-plus in the abstract. The SPS Agreement already adds upon the GATT model of purely negative integration, subjecting domestic regulations to a rationality check-up (effectiveness, proportionality, least trade restrictiveness, scientific basis, non-discrimination, consistency and convergence towards international standards). The SPS Agreement stops just short of enforcing regulatory harmonisation (Article 3) and requires mutual recognition of foreign standards (Article 4). What trade-related rules on sanitary regulations could States design that are not already covered by the SPS Agreement? ${ }^{34}$

\footnotetext{
32 Whether it could have inter partes effects is also dubious. It is sometimes argued that WTO obligations are not merely bilateral, but integral in nature view. On this debate, see C Carmody, "WTO obligations as collective" (2006) 17(2) European Journal of International Law 419; Appellate Body Report, Peru - Additional Duty on Imports of Certain Agricultural Products WT/DS457/AB/R, adopted 20 July 2015, paras 301-13; GV Puig and A Hyams, "Preferential trade agreements and the World Trade Organization: developments to the dispute settlement understanding" (2017) 44(3) Legal issues of economic integration 237, 250 (noting that WTO-minus rules seem only permissible if they are indispensable for an otherwise WTO-plus preferential agreement to operate).

33 This taxonomy is borrowed from Blümer et al, supra, note 13.

34 Generally, on the SPS provisions of FTAs, see LA Jackson and H Vitikala, "Cross-cutting issues in regional trade agreements: sanitary and phytosanitary measures" in R Acharya (ed.), Regional Trade Agreements and the Multilateral Trading System (Cambridge, Cambridge University Press 2016) pp 316-70; S Stone and F Casalini, "Sanitary and phytosanitary measures" in A Matoo et al (eds), Handbook of Deep Trade Agreements (Washington, DC, World Bank 2020) pp 367-90.
} 
SPS-plus provisions tend to focus on enhanced regulatory cooperation. ${ }^{35}$ Regulatory diversity, as such, can hinder trade; therefore, minimising regulatory idiosyncrasy promotes economic integration. Commitments and protocols on transparency (of rules) and consultation (about rules) can further this goal. ${ }^{36}$ Occasionally, ${ }^{37}$ SPS-plus provisions can go as far as establishing harmonised rules on a certain regulatory processes (eg on the management of LLP) or even harmonised substantive rules (eg on the maximum levels of LLP or harmonised approaches to precision biotechnology ${ }^{38}$ ).

In most FTAs, SPS chapters add little to the SPS Agreement, ${ }^{39}$ even when it comes to provisional SPS measures. ${ }^{40}$ Often, there is an express carving out of the SPS chapter from the dispute resolution method established by the FTA. ${ }^{41}$ The implications are clear: there is very little "plus" in the average FTA SPS chapter, and whatever "plus" there might be, it is often unenforceable. ${ }^{42}$

SPS chapters are not the only repository of trade rules on GM products and norms referring to the precautionary principle. Reference to the precautionary principle, in fact, is more common in environmental chapters - but those references would not cover the use of precaution to avoid health threats and, therefore, are only marginally relevant to the issue of marketability of GMO-containing foodstuffs and feed. More recently, certain treaties have included provisions on trade and biotechnologies in their general sections on market access and national treatment for goods, or the chapters on agriculture.

\section{The US AND EU APPROACHES}

\section{The US approach}

The US could have just been satisfied with the outcome of Biotech. However, pushing SPS-plus provisions to dispel any margin of manoeuvre for importing markets is certainly possible, as well as is addressing novel and/or specific matters, such as LLP.

\footnotetext{
35 K-J Ni, "Science and risk analysis in CPTPP/SPS-plus: role model or unbearable burden" (2019) 15 Journal of Food Law and Policy 22; Wagner, supra, note 11, 450-51.

36 Stone and Casalini, supra, note 34, 369.

37 Establishment of a binding standard is rare, see ibid, 384: "Only a small share of agreements specifically address international standards. Of the 63 agreements that do, only 10 have binding provisions".

38 See Communication to the SPS Committee from Argentina, Australia, Brazil, Canada, the Dominican Republic, Guatemala, Honduras, Paraguay, the USA and Uruguay, International Statement on Agricultural Applications of Precision Biotechnology, 26 October 2018, G/SPS/GEN/1658/Rev.3.

39 Jackson and Vitikala, supra, note 34, 362: "typically the majority of [regional trade agreements] with SPS provisions do not go beyond the rights and obligations detailed in the WTO SPS Agreement".

40 For instance, see Art 6.8(3) of the Peru-Australia FTA (PAFTA): "Recognising the Parties' rights and obligations under the relevant provisions of the SPS Agreement, nothing in this Chapter shall be construed to prevent a Party from: ... adopting or maintaining an SPS measure on a provisional basis". See also Pacific Agreement on Closer Economic Relations Plus (PACER Plus), Art 5(5). In this article, I do not survey the clauses relating to urgency or emergency measures. In the trade treaty of the African Continental Free Trade Area (ACFTA), the SPS provision corresponding to Art 5.7 of the SPS Agreement is an almost exact replica, with the exception that the period for review of provisional measures is agreed between the parties, see Art 5.4 of Annex 7.

41 PAFTA, Art 6.12; Australia-China FTA, Art 5.10.

$42 \mathrm{Ni}$, supra, note 35, 24: "most of the agreements have shown little interest in pushing for the establishment of an advanced system for risk-based regimes beyond that of the WTO's original mechanism".
} 
The US is also on record as worrying about the regulatory influence that the EU and other WTO members might deploy through their FTAs. In February 2019, when the US Trade Representative (USTR) listed its negotiation goals for an FTA with the UK, the US did not simply mention the prompt removal of "unwarranted SPS barriers that block the export of U.S. food and agricultural products" to the UK. ${ }^{43}$ The US also wished to:

Obtain commitment that the UK will not foreclose export opportunities to the United States with respect to third-country export markets, including by requiring third countries to align with non-science based restrictions and requirements or to adopt SPS measures that are not based on ascertainable risk. ${ }^{44}$

In other words, the UK promise to give up any SPS-minus precautionary temptation to please the EU would not satisfy the US. The US also wants the UK to refrain from pushing the precautionary agenda with third countries in order to prevent a whack-amole scenario. This is not an occasional demand: the USTR has regularly included it, such as its recent negotiations with Kenya, ${ }^{45}$ and even with the EU itself. ${ }^{46}$

\section{a. Lessons from the Comprehensive and Progressive Agreement for Trans-Pacific Partnership}

The Comprehensive and Progressive Agreement for Trans-Pacific Partnership (CPTPP) virtually replicates the text of the US-inspired and US-abandoned Trans-Pacific Partnership (TPP). It is, therefore, a reliable proxy of the US position.

In the SPS chapter, the CPTPP-specific language appears to monitor strictly any margin for precaution. SPS measures diverging from international standards require "documented and objective scientific evidence that is rationally related to the measures", displaying more emphasis on science than the corresponding language in the SPS Agreement. ${ }^{47}$ However, disputes relating to this clause are outside the jurisdiction of the dispute settlement system established by the CPTPP. The treaty confirms the right to take provisional measures under the SPS Agreement ${ }^{48}$ - thus locking in the status quo.

Outside the SPS chapter, the CPTPP contains a specific clause in the chapter on national treatment and market access for goods (Chapter 2, in Section $\mathrm{C}$ on agriculture) dedicated to "products of modern biotechnology" (PMBs).

This lengthy clause ${ }^{49}(1)$ imposes specific obligations of transparency on the national procedures of authorisation of PMBs, (2) devotes detailed provisions to the management of LLPs and (3) establishes a Working Group to consult and exchange information on trade in PMBs. The LLP clause creates cooperation protocols and bestows obligations of

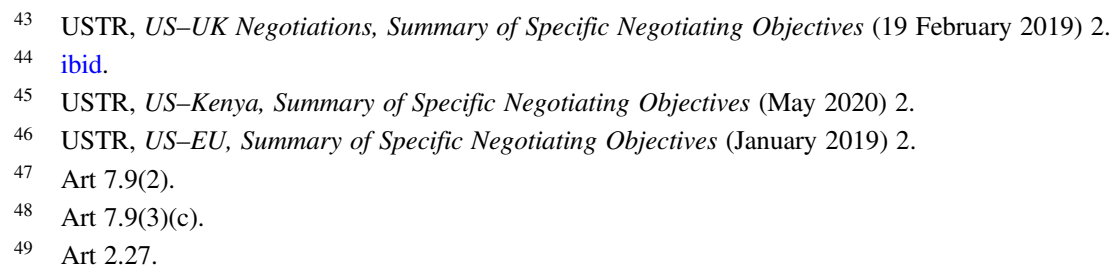


transparency and information on the importers, the importing country and the exporting country. These provisions are clearly "offensive", in that they seek "[t]o reduce the likelihood of trade disruptions from LLP occurrences" ${ }^{50}$ Hence, the inclusion of rules on LLP management in a trade agreement is squarely in the interest of PMB exporters. ${ }^{51}$

These measures are not treated as SPS measures (with emphasis on their health-driven goals), but more crudely as hindrances to trade; the treaty clauses apply whatever the motives of the domestic rules on biotechnologies. Transparency and consultation reduce the unnecessary trade frictions caused by regulatory fragmentation. By forcing importing countries to notify, explain and expose their restrictive policies, these rules increase accountability and, therefore, limit the margin for undue delays and arbitrary dragging (the Biotech scenario). LLP-related clauses, in turn, reflect the awareness that importing countries might use stringent LLP management rules to stifle PMB imports (a recurring scenario in the controversy between GM-exporting countries and the EU).

\section{b. The US-China "Phase One" deal}

In the so-called "Phase One" 2020 deal between the US and China, ${ }^{52}$ the US pushed its GMO agenda forcefully. The text emphasises how biotechnologies "improve lives by helping to feed growing populations, by reducing the environmental impact of agriculture, and by promoting more sustainable production". ${ }^{53}$ Indeed, trade in biotechnology is the subject of a dedicated Annex. ${ }^{54}$ Its provisions respond to the US offensive interest in resolving the longstanding issue of US biotech products facing convoluted and lengthy approval processes in China. ${ }^{55}$ The Annex, apart from the introductory section, does not set obligations for both parties, but is addressed only to China. Like the wider Phase One deal in which it is included, this is a purely "offensive" document, with which the US seeks to constrain its partner's regulatory autonomy and obtain market access for its own exports.

China committed to issue its decision on an approval applications within twenty-four months, ${ }^{56}$ to establish a new "simplified, predictable, science- and risk-based, and efficient" procedure for approval, ${ }^{57}$ to minimise trade disruptions caused by "inadvertent or technically unavoidable LLP occurrences"58 and to collaborate internationally on finding "practical approaches" to LLP. 59

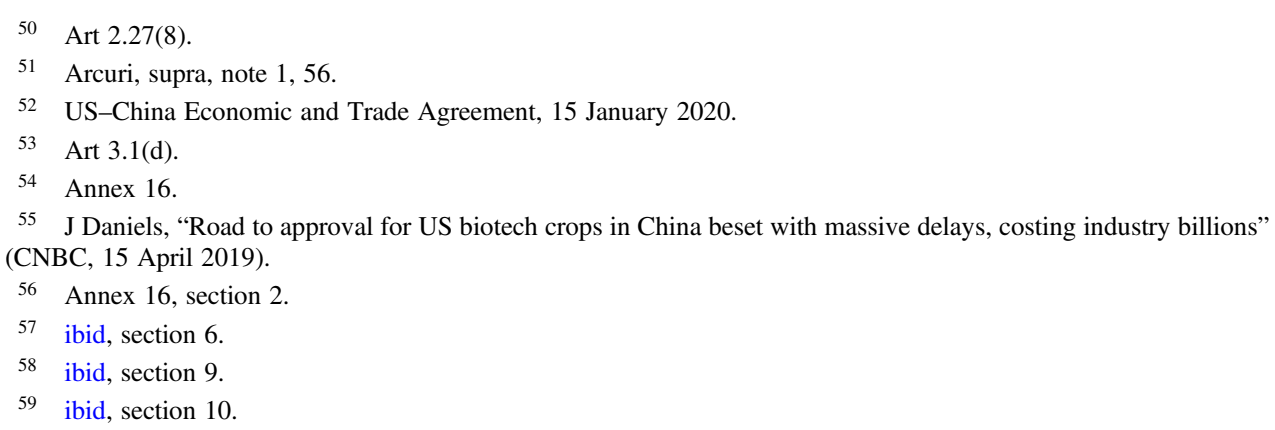




\section{The EU approach}

\section{a. EU FTAs}

In the 2017 Association Agreement with Ukraine and the 2014 Association Agreement with Moldova, the precautionary principle and preventative action figure among the chief foundations of environmental policies. ${ }^{60}$ One goal of the cooperation between the parties in the field of agriculture is precisely "promoting modern and sustainable agricultural production, respectful of the environment and of animal welfare, including ... the use of biotechnologies, inter alia through the implementation of best practices in those fields". ${ }^{61}$ This provision is vague, and there are no further references to trade in biotechnologies. The lack of GM-specific provisions is not surprising. Moldova and Ukraine are moving towards accession to the EU and have already committed to full regulatory alignment, including on GM crops. ${ }^{62}$ Therefore, the risk of regulatory differences resulting in trade barriers is virtually non-existent, and so is the need to create international obligations to prevent or police them.

The FTAs with Singapore and Vietnam, entered into force in 2019 and 2020, respectively, are not much different. The dearth of GMO-related clauses has a different root: these countries are not keen on changing their GMO-friendly stance. ${ }^{63}$ The precautionary principle is name-dropped in the chapters on environment ${ }^{64}$ and sustainable development (combining environment and labour protection). ${ }^{65}$ Outside the environmental field, precaution is not referred to, and the SPS chapters contain a sober reminder that "[e]ach Party shall adopt only measures that are scientifically justified, consistent with the risk involved and that represent the least restrictive measures available and result in minimum impediment to trade". ${ }^{66}$ One noticeable addition is the parties' commitment in the FTA with Vietnam to take the Cartagena Protocol seriously and protect biological diversity, including by taking trade measures to "reduc[e] pressure on biological diversity". ${ }^{67}$ Outside the environmental field, therefore, EU FTAs do not attempt to codify commitments of leniency for trade-restrictive regulations, let alone push the EU's partners to modify their approach to biotechnologies.

\section{b. The texts of the UK-EU FTA drafts, the Trade and Cooperation Agreement and the draft EU-MERCOSUR FTA}

The EU published in May 2020 a text for the UK-EU FTA, on which negotiations were underway in mid-2020. ${ }^{68}$ This text was little more than a working document, but it

\footnotetext{
60 Art 292(4) (Ukraine); Art 372 (Moldova).

61 Art 404(c) (Ukraine); Art 68 (Moldova) (which refers to modernisation without reference to GM crops expressly).

62 Annex IV-C to Chapter 4 and Annex XXXVIII to Chapter 17 (Ukraine), Annex XVI and Annex XVII-C (Moldova).

63 As of April 2020, Singapore has approved forty-three GM crops for use as food or food ingredients (see < sfa.gov. $\mathrm{sg}>$ ) and imposes no labelling requirements. In Vietnam, there are labelling requirements, but production and importation are authorised and there have not been LLP/[adventitious presence] situations (from $<$ fao.org $>$ GM Foods Platform country profile).

64 Art 13.11 (Vietnam).

65 Arts 12.5 and 12.9 (Singapore).

66 Art 6.6(2) (Vietnam); Art 5.6(d) (Singapore).

67 Art 13.7(3)(c).

68 European Commission <https://ec.europa.eu/info/sites/info/files/200318-draft-agreement-gen.pdf>.
} 
certainly illustrates the EU's “pie-in-the-sky” FTA language, and it contains some helpful pointers on how the EU seeks to conduct its post-Biotech external trade strategy.

There is an emphasis on biological diversity and the prevention of the "spread of invasive alien species", ${ }^{69}$ which can also affect (and vindicate) restrictions on GMOs premised on environmental protection and the protection of biological diversity. When it comes to SPS provisions, the draft offers little worth noticing. Article SPS.13 on provisional measures is a verbatim replica of Article 5.7 of the SPS Agreement, with one interesting exception. The SPS Agreement authorises provisional measures adopted "on the basis of available pertinent information, including that from the relevant international organizations as well as from sanitary or phytosanitary measures applied by other Members". ${ }^{70}$ The EU draft, instead, removes the reference to third countries' measures, which is both understandable (there are no "other members" in a bilateral FTA) and convenient (the EU would find it difficult to point at third countries' measures to show that its policies are mainstream).

Interestingly, the UK draft for the same negotiation, published two months later, did not even contain a reference to the right to adopt provisional measures. ${ }^{71}$ The omission is not necessarily meaningful (the clause proposed by the EU is redundant), but it might have signalled the UK's readiness to seize the Brexit opportunity to jump ship. Abandoning the SPS-minus approach of the EU - reflected in its internal practices and trade interests - the UK might have considered (or just threatened) to align its external trade policy with the US, and so lay the grounds for an FTA with it. In January 2021, the UK Department for Environmental Food and Rural Affairs launched a public consultation about the regulation of genetic technologies. ${ }^{72}$ The explicit goal of the consultation is to assess the desirability of "chang[ing] the legislation to amend the definition of a GMO" in order to carve out organisms produced by gene editing, diverging sharply from EU law and modified retained legislation.

The Trade and Cooperation Agreement between the UK and EU (TCA) ${ }^{73}$ includes a dedicated clause to the precautionary approach that applies in the fields of environmental and health protection, and it can apply (among other things) to the regulation of biotechnologies:

The Parties acknowledge that, in accordance with the precautionary approach, where there are reasonable grounds for concern that there are potential threats of serious or irreversible damage to the environment or human health, the lack of full scientific certainty shall not be used as a reason for preventing a Party from adopting appropriate measures to prevent such damage. ${ }^{74}$

69 Part 2, Title III "Level playing field and sustainability", Art 2.43(2)(d).

70 Emphasis added.

71 UK Government, DRAFT UK-EU Comprehensive Free Trade Agreement (CFTA) of 19 May 2020, available at $<$ https://www.gov.uk/government/publications/our-approach-to-the-future-relationship-with-the-eu>.

72 UK Government <https://consult.defra.gov.uk/agri-food-chain-directorate/the-regulation-of-genetictechnologies/>.

73 Signed on 24 December 2020, provisionally in force since 1 January 2021.

74 TCA, Part II, Heading One: Trade, Title IX on Level Playing Field, Art 1.2(2). 
Effectively, this is a defensive insurance for the EU. The UK enters into no obligation other than cutting some slack to the EU. The EU can take trade-restrictive measures designed to protect from harm that is not proved but causes "reasonable grounds for concern". The UK is free to move in any direction it wants, but it cannot complain under the TCA about the EU standards and restrictions, including with respect to biotechnology. This is a "let's agree to disagree" clause, and a footnote to the same TCA provision (Title XI of Heading One of Part II, Article 1.2) makes this very clear. In the territory of the EU, the "precautionary approach refers to the precautionary principles", thus reflecting its legal force as a principle of EU law. Instead, the UK is only expected to observe the softer and anodyne "approach".

Ultimately, the TCA appears to have opted for a reasonable pact of non-aggression regarding biotechnologies and precautionary restrictions at large. As explained above (Section III.2), FTAs cannot displace SPS rules, but they may introduce defensive clauses whereby certain restrictive measures (eg precautionary bans) are not considered actionable by the parties. ${ }^{75}$ This result is about the best SPS-minus result that the EU can extract from a bilateral deal with a no-longer-aligned trade partner.

The negotiation between the EU and MERCOSUR, on the contrary, pins the GMsceptical and the GM-friendly approaches against each other, since the MERCOSUR parties are among the biggest producers and exporters of GM crops. The Commission typically guaranteed that the EU would maintain its "strict approach on genetically modified organisms". ${ }^{76}$ The parties reached in mid-2019 an "agreement in principle". A mention of the precautionary approach appears in the chapter on trade and sustainable development. ${ }^{77}$ Critically, there is a chapter on "Dialogues" addressing, among other topics, "issues related to the application of agricultural biotechnology" 78 This chapter builds on, and replaces, the Mutually Agreed Solution reached by the EU and Argentina in the wake of the Biotech case, ${ }^{79}$ and it expressly establishes regulatory coordination on issues such as LLP and asynchronous authorisations. In this FTA, the EU failed to include the non-aggression clause of the TCA with the UK, but it did not concede much to the MERCOSUR's offensive goals. This resistance already seems to have been a decent achievement for the EU, given that the EU counterparts include Argentina, and any hope of successful negotiation on GMOs with Argentina was precluded by the post-Biotech settlement.

\section{FTAS WITH THE SAME THIRD COUNTRIES}

\section{FTAs with Canada: the Comprehensive Economic and Trade Agreement between the EU and Canada and the US-Mexico-Canada Agreement}

If the strategies of the EU and US are measured based upon their post-Biotech FTAs, the Comprehensive Economic and Trade Agreement between the EU and Canada (CETA) is

\footnotetext{
75 This is confirmed by the language of Art SPS.4, which reaffirms the rights and obligations of the SPS Agreement and, very redundantly, expressly mentions "the right to adopt measures in accordance with Article 5(7)" thereof.

76 European Commission, EU-MERCOSUR - Respecting Europe's food safety standards (June 2019), available at $<$ https://trade.ec.europa.eu/doclib/docs/2019/june/tradoc_157956.pdf $>$.

77 Art 11.

78 Art 1.

79 Art 4, footnote 1.
} 
a significant document to examine. ${ }^{80}$ The position of Canada presumably aligns with the US one, by dint of the free trade deal between them ${ }^{81}$ and in light of its longstanding favour towards GM crops. ${ }^{82}$ CETA, therefore, should reveal how the EU and the North American positions can be reconciled or whether either one prevails. Moreover, the text of CETA can be contrasted with the text of the novel USMexico-Canada Agreement (USMCA; the new North American Free Trade Agreement (NAFTA)), a "pure breed" of North Americanism in the field of trade in biotechnologies.

\section{a. CETA}

In the preamble of the joint interpretative instrument annexed to CETA, the EU and Canada reaffirmed "the commitments with respect to precaution that they have undertaken in international agreements". Canada has signed, but not ratified, the Cartagena Protocol to the Convention on Biodiversity, but it is fair to interpret "respect to precaution" severally; that is, based on the international commitments of each party (not of both). ${ }^{83}$

The European Commission's spin on CETA borders on the disingenuous. In a promotional document, it states that in CETA "the precautionary principle [is] upheld", and it explains that CETA "refers to the right to regulate and to the principles underlying the regulatory regime of each party". ${ }^{84}$ These declarations are accurate only with respect to the parties' right to prevent environmental degradation, ${ }^{85}$ but they do not reflect CETA's approach to SPS measures, which are by definition health-related. While it is plausible to argue that CETA has grandfathered the EU's SPS precautionary rules at the time of conclusion, it is more difficult to assume that the EU can adopt new ones without fear of CETA-based challenges. The right to keep in place existing regulations is not the same as the "right to regulate".

Unsurprisingly, the operative provisions of CETA do not embed the baseline position of either party, ${ }^{86}$ and they set up instead a suite of processes to manage (rather than resolve ex ante) potential disagreements. The actual language of CETA does not echo the Commission's promotional profession of immunity for EU policies. The EU and Canada established a "Dialogue on Biotech Market Access Issues" for the parties to address regulatory restrictions, a direct legacy of the post-Biotech settlement deal. ${ }^{87}$

\footnotetext{
80 The now defunct Trans-Atlantic Trade and Investment Partnership (TTIP) would have been even more pertinent, but it was shelved before reaching a draft text worth discussing.

81 NAFTA and USMCA.

82 SJ Smyth, "Canadian regulatory perspectives on genome engineered crops" (2017) 8(1) GM Crops \& Food 35.

83 See also Art 24.3 in the chapter on trade and environment, which refers to the multilateral environmental agreements of each party.

84 European Commission, "Safeguards in CETA", CETA Factsheet no. 4 (September 2017), available at <https:// trade.ec.europa.eu/doclib/docs/2017/september/tradoc_156060.pdf $>$.

85 See Art 24.8(2): "The Parties acknowledge that where there are threats of serious or irreversible damage, the lack of full scientific certainty shall not be used as a reason for postponing cost-effective measures to prevent environmental degradation".

86 Arcuri, supra, note 1.

87 Art 25.2.
} 
Canada's call to "pragmatism" with respect to LLP, quoted in the introduction of this article, was made precisely during the 2019 session of this institutionalised Dialogue.

Given the starting positions of the two parties (and their transactional origin), the Dialogue is essentially a venue of contestation for Canada against the EU's measures that might deny market access to its exports and for the EU to defend their rationale. ${ }^{88}$ Canada produces and exports GM products, while the EU produces almost none; the EU opts for zero or low tolerance, while Canada prefers a nuanced LLP management system. ${ }^{89}$ Article 25.2 states that "cooperation and information exchange on issues in connection with biotechnology products are of mutual interest", but that is true only in the abstract. Canada's trade interest is that the EU remove or avoid undue restrictions; the EU societal interest would have been better served by a lack of dialogue, but the concessions of the 2009 settlement are unavoidable. Since CETA does not appear to provide a solid ground for the EU's take on precautionary measures on health matters, trade concerns or disputes cannot be ruled out in light of the EU's unflinching approach described above (Section II).

The strong emphasis on cooperation and the apparent grandfathering of existing measures defuse or delay the risk of open trade controversies in the short term. In this sense, both parties can claim to have protected their status quo in CETA, but in the medium or long term there is no guarantee that the EU can dodge the pressure from Canadian exporters if its objections remain unassisted by science. ${ }^{90}$

\section{b. USMCA}

USMCA (the revamped NAFTA) has, predictably, fewer constructive ambiguities than CETA. From the preamble, the parties resolve to protect human health and contextually "advance science-based decision making".

The SPS chapter purports to "reinforce and build upon the SPS agreement", 91 but the relevant provisions on the "provisional measures" mimic Article 5.7 SPS and, therefore, add very little to it. ${ }^{92}$ It is true that

both the USMCA's and CPTPP's emphases on "science-based risk management" undermine the "precautionary principle" (when evidence is unclear or the policy process prone to regulatory capture, err on the side of caution), a principle which

\footnotetext{
88 Arcuri, supra, note 1, 48.

89 Canadian Government, Policy Model - Managing Low Level Presence of Genetically Modified Crops in Imported Grain, Food and Feed (2017), available at <https://www.agr.gc.ca/eng/international-trade/agri-food-trade-issues/ technical-trade-issues-in-agriculture/policy-model-managing-low-level-presence-of-genetically-modified-crops-inimported-grain-food-and-feed/?id=1472836695032 $>$.

90 On the largely performative professions of the Commission that CETA will not undermine the use of EU-style precaution, see WT Douma, "The limits to precaution in international trade law: from WTO law to EU trade agreements", in L Squintani et al (eds), Managing Facts and Feelings in Environmental Governance (Cheltenham, Edward Elgar 2019) pp 163, 198-99.

91 Art 9.3 .

92 See Arts 9.6(4)(c) and 9.6(5).
} 
remains embedded in EU law (and its trade policy) and is considered an important public health ethic. ${ }^{93}$

However, the USMCA's (and CPTPP's) strict language is not a strategic attack on the EU model. The mere repetition of, or reference to, the SPS's emphasis on science is sufficient for the US to confirm its trade and risk-management preferences in trade relations. There is no need for SPS-plus for the US to stifle precautionary agendas of the EU variety - SPS-equal is enough.

A plus element of USMCA is the range of specific provisions on agricultural biotechnology in the chapter on agriculture, which largely mirror the rules on market access and national treatment for PMBs of CPTPP. Compared to the CPTPP text, the opening provision of this dedicated section" ${ }^{94}$ adds the parties' confirmation of "the importance ... of facilitating trade in products of agricultural biotechnology". This addition betrays the common preference of the three USMCA parties, which are unanimously keen on dismantling, rather than permitting, regulatory barriers to GM products. Like CPTPP, USMCA contains a detailed regime for LLPs ${ }^{95}$ and establishes a Working Group for the parties to consult on trade concerns. ${ }^{96}$ The USMCA text is perhaps to date the most incisive SPS-plus instrument when it comes to liberalising trade in biotechnologies. ${ }^{97}$

\section{FTAs with Japan and Korea}

This section reviews the FTAs with Japan and South Korea. Both the US and EU have FTAs with Korea; Japan's FTA with the EU is already in force, while it is negotiating one with the US.

\section{a. Korean FTAs with the US and EU}

GM-containing food in Korea suffers from the kind of stigmatisation that is common in the EU. ${ }^{98}$ In this respect, the comparison of the Korean deals with the EU (2015) and the US (2012) might be interesting.

The US's FTA with Korea (KORUS) does not add anything salient to the WTO regime (which, as explained, is already a decent baseline for the US agenda and gives it an upper hand over GMO-unfriendly trade partners). The SPS chapter ${ }^{99}$ is two pages long and, besides reiterating compliance with the SPS Agreement, creates a bilateral Committee

93 R Labonté et al, "USMCA (NAFTA 2.0): tightening the constraints on the right to regulate for public health" (2019) 15(1) Globalization and Health 1, 6.

94 Art 3.14(1).

95 Art 3.15 .

96 Art 3.16.

97 US Congressional Research Service, "U.S.-EU Trade Agreement Negotiations: Trade in Food and Agricultural Products" (27 February 2020) CSR Report R46241, 17.

98 RB Kim, "Consumer attitude of risk and benefits toward genetically modified (GM) foods in South Korea: implications for food policy” (2012) 23(2) Engineering Economics 189.

99 Chapter 8, Arts 8.1-8.4. 
and rules out the possibility of litigating any provision of the chapter through the FTA dispute settlement system.

The EU-Korea FTA (EUFTA) predictably does not address biotechnologies at all. For two countries that are keen to preserve their regulatory autonomy, the fewer commitments the better. Contrast the silence on this issue with the precise regulation of precautionary measures restricting trade in cars and car parts:

Neither Party shall prevent or unduly delay the placing on its market of a product on the ground that it incorporates a new technology or a new feature which has not yet been regulated unless it can demonstrate, based on scientific or technical information, that this new technology or new feature creates a risk for human health, safety or the environment. ${ }^{100}$

Moreover, measures restricting trade in cars are permitted if they are necessary to protect public health, but only if they are "based on substantiated scientific or technical information". ${ }^{101}$

It transpires clearly that the commonplace idea that the EU (or South Korea) considers the precautionary principle a negotiating red line is a simplification. To facilitate trade in cars, which is perhaps the single biggest reason for this FTA to exist, the EU is happy to expressly trade away its power to take precautionary measures on product safety. The EU's position on food safety is partially about a specific EU approach to risk management and a lot about local societal preferences.

\section{b. Japanese FTAs with the US and EU}

Japan has formally approved the cultivation of many GM products, but no commercial cultivation has ever occurred (except for a decorative GM rose variety), and GMcontaining foods raise concerns among the population. ${ }^{102}$

The US and Japan concluded in late 2019 a mini-FTA applicable only to agricultural products, ${ }^{103}$ with no provision on biotechnologies or precaution. ${ }^{104}$ A full-fledged FTA is, allegedly, in the works. ${ }^{105}$

Japan's 2018 deal with the EU is, likewise, silent on trade in GM products. The precautionary principle is not missing altogether. In the chapter on sustainable

\footnotetext{
100 Annex 2-C Motor Vehicles and Parts, Art 6(1).

101 ibid, Art 7.

102 T Ishii, "Regulation of genome editing in plant biotechnology: Japan", in H-G Dederer and D Hamburger (eds), Regulation of Genome Editing in Plant Biotechnology: A Comparative Analysis of Regulatory Frameworks of Selected Countries and the EU (Berlin, Springer 2019) p 239.

103 For this reason, it prima facie fails to respect the requirements of Art XXIV GATT, at least until it is further extended to other sectors.

104 See how a study by the US Congressional Research Survey characterises this aspect in “'Stage One' U.S.-Japan Trade Agreements" (20 December 2019) CSR Report R46140, 8: "Lack of legal text on non-market-access provisions, such as agricultural biotechnology, geographical indications, sanitary and phytosanitary measures, and technical barriers to trade (TBT) in the [US-Japan Trade Agreement] may limit the United States' ability to challenge potential future trade barriers in Japan (and vice versa) related to these issues, for example, if Japan were to align its requirements for agricultural imports more closely with those of the EU or of TPP-11 countries".

105 In September 2020, the Japanese government did not list the US among the partners with which an FTA was "under negotiation", see <https://www.mofa.go.jp/policy/economy/fta/index.html>.
} 
development (which does not cover health-related policies), the EU and Japan agreed to put the "precautionary approach" on par with science and international standards:

When preparing and implementing measures with the aim of protecting the environment or labour conditions that may affect trade or investment, the Parties shall take account of available scientific and technical information, and where appropriate, relevant international standards, guidelines or recommendations, and the precautionary approach. ${ }^{106}$

Like the Korea-EU FTA, the Japan-EU FTA also contains strong anti-precaution language in the Annex on cars and car parts. ${ }^{107}$ There is a prohibition against scienceless precautionary measures stifling market access for new technologies, ${ }^{108}$ as well as a stern reminder that all regulatory measures addressing public health and safety must be "based on substantiated scientific or technical information". 109

Ultimately, the EU and Japan did not forget about the precautionary principle - they just preferred to leave GM matters alone, which is the best option for reserving as much regulatory freedom as possible. After all, the EU and Japan were not worried about each other's approach on GM products: they are similarly restrictive. ${ }^{110}$ When regulatory restrictions threaten a vital part of trade, such as trade in cars, the parties diligently and explicitly rule out non-scientific restrictions.

\section{Future FTAs with African countries?}

The survey, so far, has shown that FTAs are not a favourite avenue to push the agendas of the EU and US on trade in biotechnologies at large. The US can focus on specific matters, relying on the WTO baseline. The EU perhaps has realised that silence might be the best option: with like-minded partners, words are no use; with GM-friendly partners, the less said the better, to avoid self-incrimination.

However, there are markets in which both the EU and the US could exercise meaningful regulatory influence through their trade policies. FTAs contain a promise of market access for agricultural products that, if accompanied by regulatory requirements, can shape the production methods in the exporting partners. This is particularly the case for African countries.

For instance, strict rules on LLP and adventitious presence might increase the cost of production for countries that want to trade with the EU and US and want thus to retain both GM and GM-free crop production capacities. Depending on the incentives and costs at stake, some countries might simply shift to all-GM-free or all-GM cultivation to serve

\footnotetext{
106 Art 16.9 (emphasis added).

107 Annex 2-C on Motor Vehicles and Cars.

108 ibid, Art 14.

109 ibid, Art 16.

110 Blümer et al, supra, note 13, 871: "As most countries fear targeting by foreign plaintiffs for their domestic environmental measures, we expect that the introduction in a [preferential trade agreement] of defensive provisions is more easily accepted than the introduction of offensive provisions".
} 
their biggest clients better. Since GM-free products are exportable anywhere, they stand a better chance of being chosen as a country-wide standard.

Market access requirements shape exporters' behaviour with or without FTAs. However, FTAs could push towards tailored regulations to favour trade in biotechnologies (think of the US-China Phase One deal) or contain apologetic language justifying restrictions (think of the UK-EU TCA). Currently, the outlook on African states is that they will retain their largely precautionary stance, ${ }^{111}$ and the African Continental Free Trade Area (ACFTA) does not betray a tendency in either direction. ${ }^{112}$ It will be important to see whether the US or the EU will be able to make a first move to negotiate a deal with the ACFTA, and whether they will try, through their deals, to recruit the African countries into their respective teams on the issue of trade in biotechnologies.

\section{Conclusions}

Are there two competing drafting models, reflected in the various trade agreements? Not quite.

Understandably, the US is happy to confirm its reliance on SPS-like provisions, sometimes through mere cross-references to the SPS Agreement. The US has moved away from the battle on science at large and is focusing on specific and novel issues, such as LLP management and precision biotechnology.

Conversely, the EU is not really putting up an SPS fight in FTAs to reduce the detrimental effect that the Biotech reports had on its social and trade interests on GM products. ${ }^{113}$ With like-minded countries (or countries bound to follow the EU rules), there is no need. With GM-loving countries, if you cannot touch the SPS Agreement, then there is only so much to discuss. Moreover, with Canada and MERCOSUR, the EU had to reckon with its Biotech settlement, so its hands were tied even more tightly, and it had to accept the "dialogue" arrangement in the respective FTAs.

Ultimately, this survey, conducted on a larger and updated sample of FTAs, confirms the impression of modest drafting ambition recorded in the scholarship. ${ }^{114}$ The EU's resulting approach is to drag its figurative feet - more akin to low-profile civil disobedience than long-term external trade strategy. The truce with the UK reflected in the TCA provisions is a continuation of this approach, with a nice promise of nonaggression by the UK.

\footnotetext{
111 Osiemo, supra, note 10, 161.

112 K Kuhlmann and AL Agutu, "The African Continental Free Trade Area: toward a new legal model for trade and development” (2020) 51(4) Georgetown Journal of International Law 753-808.

113 Little to no production, no exports, a preference for regulatory autonomy that can raise marketing and border barriers affecting imports.

114 AR Young, "You can drive my car, otherwise let it be: addressing product regulations in the EU's Asia-Pacific trade agreements" (2020) Working paper GTJMCE-2020-1, 9: "The agreements between the EU and Singapore, Vietnam and Japan simply affirm the parties' rights under the WTO's SPS Agreement. The EU's earlier agreement with Korea talks about developing common understandings of international standards. Thus, the EU's concluded FTA's [sic] do not advance regulatory alignment beyond the very limited efforts of the WTO's TBT and SPS Agreements".
} 
Arguably, the US model contains everything it needs to prevail as a generalised model, so it is only necessary to point out two reasons why this might not happen after all, or why it might not take everywhere. First, new scientific evidence might emerge pointing to the danger to human health posed by foodstuffs containing GMOs. If that were the case, the EU could just find comfort in the SPS Agreement, quite apart from its FTA success, and have its restrictions justified. Second, some countries might prefer to opt to retain only GM-free agriculture in order to stay in business with the EU trading bloc (a strategy that would not preclude trade with the US). Apart from these two scenarios, the North American model is silently but inevitably establishing itself as the prevailing template for global trade regimes. 